\title{
Environmental pollutants and a potential strategy to reduce the risk of diabetes
}

\author{
Lee Grenon
}

\author{
Simon Fraser University
}

The increasing prevalence of type 2 diabetes mellitus (T2DM) throughout the world is often attributed to changes in diet and a more sedentary lifestyle. ${ }^{1}$ Are there other potential underlying causes of this current pandemic? Environmental pollutants, particularly persistent organic pollutants (POPs), have been suggested by some researchers as potential contributors to the rising prevalence of diabetes as endocrine disruptors. ${ }^{2}$ POPs include organochlorine pesticides (i.e., DDT), polychlorinated biphenyls (PCBs), and polybrominated diphenyl ethers (i.e., common flame retardant compounds). These toxins are resilient to degradation in the environment and organisms. ${ }^{3}$ In this article I briefly review evidence indicating an association between POPs and T2DM, and the potential implications for public health strategies to reduce the potential risks of T2DM.

Early evidence of an association between POPs and diabetes emerged from epidemiological studies of occupational exposure, and industrial and consumer product contamination. ${ }^{2}$ Concerns for the environment and human health led to the establishment of the Stockholm Convention on Persistent Organic Pollutants to end the production and use of specific POPs in the participating nations. ${ }^{3}$ Despite being banned in many countries, POPs are still present in the physical environment and our food chain. ${ }^{3}$ POPs bind with lipids in animal adipose, organs and muscle. ${ }^{3}$ The relatively long half-life of POPs which are resilient to metabolic degradation leads to bioaccumulation in plants and animals. ${ }^{3}$ This bioaccumulation of POPs in fatty fish such as salmon and tuna, and in dairy and meat livestock, is the major exposure source for most people. ${ }^{3}$

Studies of the US population using the National Health, Nutrition and Examination Survey (NHANES) have found increased serum levels of POPs are associated with greater insulin resistance among non-diabetics and increased odds of type 2 diabetes. ${ }^{4,5}$ Two recent animal studies have provided important insights into the possible biological pathway through which POPs may contribute to insulin resistance and obesity. ${ }^{6,7} \mathrm{Ibrahim}$ and colleagues recently reported that protein kinase $B$ (PKB) phosphorylation is suppressed by exposure to POPs. ${ }^{6}$ Protein kinase $\mathrm{B}$ is a well conserved signaling pathway across a diverse range of species ${ }^{8}$ and important for many metabolic functions. It is particularly important for insulin signaling in a variety of target tissues including adipose, muscle, liver and pancreas. ${ }^{8}$ The insulin-stimulated PKB phosphorylation is integral for increasing glucose transport into adipocytes and muscle cells.

The epidemiological evidence has not reported consistent findings on an association between POPs and diabetes. ${ }^{2}$ However, the experimental studies provide a biologically plausible hypothesis that POPs in tissue suppress PKB phosphorylation. Further research is needed to determine with greater certainty the nature and extent of the association between the exposure to POPs and the increase in the risk of insulin resistance and type 2 diabetes in human populations. A better assessment of the risk is necessary for weighing the benefits and costs of strategies to mitigate the exposure to POPs.

However, we could propose a variety of strategies to mitigate exposure to these pollutants by applying the precautionary principle. This approach aims to prevent public exposure to a plausible risk even when there is not scientific consensus on the extent or potential of harm. However, the potential unintended consequences of such strategies need to be carefully considered. One strategy could focus on reducing dietary exposure among humans. For example, dietary recommendations to replace consumption of fatty fish and marine mammals with leaner species may reduce exposure to POPs. ${ }^{6}$ However, such a strategy needs to be carefully discussed and considered in terms of the assessed risks among all stakeholders 
since these fisheries are an important protein source for populations throughout the world. As an example, the maintenance of local food harvest practices in Inuit and First Nations communities is important for supporting healthy diet choices, improving economic self-sufficiency and cultural continuity. ${ }^{9,10}$ Broad generic food advisories concerning pollutant contamination of fish and animals have generated anxiety and a loss of trust in local foods for some communities ${ }^{10}$ Well intentioned warnings to reduce exposure to POPs and other pollutants in fish may have the unintended consequence of increased anxiety over local food safety in general. The loss of trust in local foods can lead to decreased local food harvesting practices resulting in increased consumption of processed products high in carbohydrates, sugar and salt, greater reliance on food systems outside the communities and decreased culturally appropriate land-use practices. ${ }^{9,10} \mathrm{~A}$ reduction in local food harvesting may have significant consequences for the physical activity levels and cultural practices of people in these communities already experiencing relatively high prevalence of both obesity and diabetes. ${ }^{9,10}$

Further research to assess specific risks associated with exposure to POPs is necessary to inform the development of effective strategies for reducing the risks of diabetes. These various dimensions of evidence suggest it is necessary to directly engage communities and groups most affected by these types of public health strategies to ensure optimized benefits and reduced costs for all communities.

\section{Acknowledgments}

I would like to thank Dr. Scott Venners for helpful comments on an earlier version of this article.

\section{References}

1. Roberts CK, Barnard RJ. Effects of exercise and diet on chronic disease. Journal of Applied Physiology. 2005;98(1):3-30.

2. Carpenter D. Environmental contaminants as risk factors for developing diabetes. Reviews on Environmental Health. 2008;28(1):59-74.

3. Harrad, S. (ed). Persistent Organic Pollutants. West Essex, UK: Wiley; 2010.

4. Lee DH, Lee IK, Song K, Steffes M, Toscano W, Baker BA, et al. A strong doseresponse relation between serum concentrations of persistent organic pollutants and diabetes: results from the National Health and Examination Survey 1999-2002. Diabetes Care. 2006;29(7):1638-1644.

5. Lee $\mathrm{DH}$, Lee IK, Jin SH, Steffes M, Jacobs D. Association between serum concentrations of persistent organic pollutants and insulin resistance among nondiabetic adults. Diabetes Care. 2007;30(3):622-628.

6. Ibrahim MM, Fjære E, Lock E-J, Naville D, Amlund $H$, Meugnier E, Le Magueresse Battistoni B, Frøyland L, Madsen L, Jessen N, Lund S, Vidal $\mathrm{H}$, Ruzzin J. Chronic consumption of farmed salmon containing persistent organic pollutants causes insulin resistance and obesity in mice. PLOS ONE 2011;6(9):e25170.

7. Ruzzin J, Petersen R, Meugnier E, Madsen L, Lock EJ, Lillefosse $H$, Ma $T$, Pesenti $S$ et al. Persistent organic pollutant exposure leads to insulin resistance syndrome. Environmental Health Perspectives. 2010;118(4):465471.

8. Whiteman EL, Cho H, and Birnbaum MJ. The role of Akt/protein kinase B in metabolism. Trends in Endocrinology and Metabolism. 2002;13(10):444451.

9. Willows ND. Determinants of healthy eating in Aboriginal peoples in Canada: the current state of knowledge and research gaps. Canadian Journal of Public Health. 2005;96(Supp. 3):S32-S36.

10. Giles, BG, Findlay $C S$, Haas $G$, LaFrance B, Laughing $W$, Pembleton $S$. Integrating conventional science and aboriginal perspectives on diabetes using fuzzy cognitive maps. Social Science \& Medicine. 2007;64:562-576.

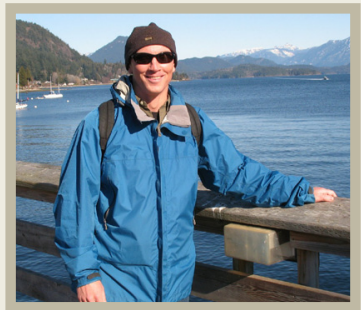

\section{Lee Grenon}

I have been an analyst with Statistics Canada since 1991. Two years ago, I began graduate studies at Simon Fraser University with a focus on environmental molecular epidemiology. My current research is on the relationship of persistent organic pollutants with insulin metabolism. 